\title{
Overweight, asthma symptoms, atopy and pulmonary function in children of 4-12 years of age: findings from the SCAALA cohort in Salvador, Bahia, Brazil
}

\author{
Sheila MA Matos ${ }^{1, *}$, Sandra R Jesus ${ }^{2}$, Silvia RDM Saldiva ${ }^{3}$, Matildes S Prado ${ }^{1}$, \\ Silvana D'Innocenzo ${ }^{1}$, Ana MO Assis ${ }^{4}$, Laura C Rodrigues ${ }^{5}$, Neuza M Alcantara-Neves ${ }^{6}$, \\ Álvaro A Cruz ${ }^{7}$, Silvia de Magalhães Simões ${ }^{8}$ and Maurício L Barreto ${ }^{1}$; SCAALA (Social \\ Change, Asthma and Allergy in Latin America) Study Group \\ ${ }^{1}$ Instituto de Saúde Coletiva, Universidade Federal da Bahia, Rua Basílio da Gama, s/nº, Campus Universitário \\ do Canela, $5^{\circ}$ andar, $40110-040$ Salvador, Bahia, Brazil: ${ }^{2}$ Núcleo de Epidemiologia e Saúde Coletiva, Instituto \\ Multidisciplinar em Saúde, Universidade Federal da Bahia, Brazil: ${ }^{3}$ Instituto de Saúde, Secretaria do Estado da \\ Saúde de São Paulo, Brazil: ${ }^{4}$ Escola de Nutrição, Universidade Federal da Bahia, Brazil: ${ }^{5}$ Department of \\ Epidemiology and Populations Health, London School of Hygiene and Tropical Medicine, UK: ${ }^{\text {Instituto de }}$ \\ Ciências da Saúde, Universidade Federal da Bahia, Salvador, Bahia, Brazil: ${ }^{7}$ ProAR, Faculdade de Medicina \\ da Bahia, Universidade Federal da Bahia, Salvador, Brazil: ${ }^{8}$ Departamento de Medicina, Universidade Federal \\ de Sergipe, Aracaju, Sergipe, Brazil
}

Submitted 5 July 2010: Accepted 9 February 2011: First published online 13 April 2011

\begin{abstract}
Objective: To evaluate the association between overweight and the occurrence of asthma and atopy in a cohort of children of 4-12 years of age living in the city of Salvador in 2005.

Design: Cross-sectional study nested in a cohort.

Setting: The metropolitan region of Salvador, Bahia, Brazil.

Subjects: The study included 1129 children of 4-12 years age who presented complete information on the variables used here. Skin tests for allergy, spirometry, faecal parasitology, serum IgE and anthropometric surveys were conducted. Poisson's multivariate regression was adopted.

Results: Wheezing was found in $29 \cdot 1 \%$ and asthma in $22 \cdot 8 \%$ of children, both conditions being more common in those under 6 years of age and $34 \%$ more common in overweight children (prevalence ratio $(\mathrm{PR})=1 \cdot 34 ; 95 \%$ CI 1.07, 1.67) following adjustment. The ratio between forced expiratory volume in $1 \mathrm{~s}$ and forced vital capacity was associated with overweight ( $\mathrm{PR}=1 \cdot 35 ; 95 \% \mathrm{CI} 1 \cdot 11,1 \cdot 61)$. No statistically significant association was found between overweight and allergen-specific IgE or with wheezing.

Conclusions: These results are in agreement with the hypothesis that overweight is associated with asthma and pulmonary function, even following adjustment for intervening variables known to be associated with the pathogeny of asthma.
\end{abstract}

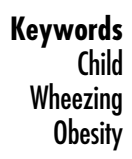

Obesity and asthma are health issues that have been the target of an expressive volume of research worldwide in recent years because of the increase in prevalence of these diseases, particularly in children and adolescents in developed countries ${ }^{(1,2)}$. Recent reviews indicate the existence of a two-way association in which asthma may contribute towards obesity and obesity may cause or aggravate asthma $^{(3,4)}$.

In Brazil, where nutritional transition occurs rapidly, a decline in malnutrition has been observed at different intensity levels in all age groups, accompanied by an increase in overweight and obesity ${ }^{(5)}$. According to phase III of the International Study of Asthma and Allergies in Childhood (ISAAC) in Brazilian schoolchildren, asthma has been reported to range from $8 \cdot 6 \%$ to $32 \cdot 1 \%$. Brazil has been among the countries in which the prevalence of this disease is the highest ${ }^{(6)}$.

Some investigators believe that this growing trend in overweight and obesity fails to explain the increase in asthma, and speculate that obesity may represent a marker of the recent changes in lifestyle associated with asthma and obesity ${ }^{(7)}$. For other authors, children with a high birth 
weight or who are overweight in infancy are at a higher risk of developing asthma in the future. Results of a recent meta-analysis corroborate this latter hypothesis ${ }^{(8)}$.

Many factors that have been investigated may play a role in the occurrence of asthma in obese individuals (e.g. genetical, mechanical devices, immunological, hormonal and environmental factors). These factors may be involved in the possible association of obesity with asthma; however, the methodological problems present in many studies render these findings inconclusive ${ }^{(9)}$. The role of inflammatory mediators produced by visceral fat in increasing subepithelial fibrosis and remodelling the airways has been studied in animal models ${ }^{(10)}$. In humans, asthma is more common in children with abdominal obesity, indicating that the proinflammatory state of insulin resistance may contribute towards the occurrence of asthma in obese patients ${ }^{(11,12)}$. The proinflammatory role of hypercholesterolaemia and leptin has been studied as a further risk factor for asthma ${ }^{(13,14)}$

There is also a discussion on whether gender may represent an additional risk factor for asthma in the obese. Under this hypothesis, obese female children would be at a greater risk for asthma at the beginning of puberty and immediately afterwards, inferring that the mechanisms involved in this period may be different from those found before puberty ${ }^{(15)}$.

The objective of the present study was to determine whether there is an association between overweight, asthma symptoms, atopy and pulmonary function in children of 4-12 years of age residing in Salvador, Bahia, Brazil.

\section{Methods}

\section{Study design}

The present paper refers to a cross-sectional, populationbased study nested within a cohort developed in 2005 in the metropolitan region of Salvador, a city of approximately 2.5 million inhabitants situated in the north-east of Brazil. Details of the methodology and the results of the first survey and of the cohort study have been described previously in detail ${ }^{(16,17)}$. The children included in the present study are part of a prospective cohort study investigating the health impact of installation of a sewage system in marginal neighbourhoods in the city of Salvador ${ }^{(16)}$. Data were collected from children born between 1994 and 2001 who lived in 'sentinel' areas scattered throughout the city. Data were collected between 1997 and 2003 (baseline) and in 2005 the children were resurveyed. In each study period different children were recruited up to a total of 2973 participants.

\section{Study population}

Of the 2973 children recruited at baseline and resident in the twenty-four micro-areas with no basic sanitation at the time of the study, 1445 children were followed up with the principal objective of studying the risk factors for the occurrence of asthma and other allergic diseases in children $^{(18,19)}$. A total of 1129 children of $4-12$ years of age who presented complete information for the variables used here were included in the present study.

\section{Data collection}

Socio-economic and environmental data and reported information on asthma symptoms were obtained using a standardized questionnaire adapted from the Portuguese version of the questionnaire used in the second phase of the ISAAC ${ }^{(18)}$ trial. The interview was conducted with the children's parents or guardians for the specific purpose of obtaining data referring to signs and symptoms compatible with asthma and allergy and their risk factors. Mothers were classified as illiterate if they reported no schooling or incomplete elementary-school education.

Asthma was defined as the reported occurrence of wheezing in the 12 months before the interview and at least one of the following: diagnosis of asthma at least once; waking up at night because of wheezing in the past 12 months; wheezing while exercising in the past 12 months; and four or more episodes of wheezing.

Birth weight and duration of breast-feeding were assessed by questions on infant feeding at baseline when children were $<3$ years of age. The parents were asked how long the child was breast-fed and whether the mother was still breast-feeding, with the duration being defined as the age at which breast-feeding stopped. The highest limit of 2 months was used as the cut-off level to obtain an even number of children in each group. Unfortunately, the degree of exclusive breast-feeding in this population is not known.

The children were weighed on portable electronic microscales (Filizola ${ }^{\circledR}$, model E-150/3P, São Paulo, Brazil) and measured using a portable stadiometer (Leicester height measure). Variations of $100 \mathrm{~g}$ were permitted for weight and $0.1 \mathrm{~cm}$ for height and length. The mean of two measurements was considered as the final measurement. The instruments were calibrated periodically. The recommended technical standards and criteria were observed in all steps of the anthropometric evaluation ${ }^{(20)}$. The children's ages were recorded from their birth certificates or from their health cards, and the difference was calculated between the measurement date and the child's date of birth. Birth weight was obtained from the child's health card. Children with BMI $Z$-scores $\geq+1$ were considered to be overweight on the basis of the 2006 and 2007 reference standards of the $\mathrm{WHO}^{(21-23)}$.

The presence of helminth eggs or protozoan cysts and oocysts in faeces, detected using the spontaneous sedimentation $^{(24)}$ and/or the Kato-Katz techniques ${ }^{(25)}$, was considered as an indication of a positive parasitology test.

Skin tests were conducted on the right forearm of each child using extracts (ALK-Abello, São Paulo, Brazil) for 
the following allergens: cat epithelium, dog epithelium, Dermatophagoides pteronyssinus (house dust mite), Blomia tropicalis (tropical dust mite), Blattella germanica (German cockroach), Periplaneta americana (American cockroach) and a mixture of fungi. Saline solution and histamine were used as negative and positive controls, respectively ${ }^{(18)}$. The size of the skin wheal reaction was read after $15 \mathrm{~min}$ and the test was considered positive if the mean of the two perpendicular diameters (excluding the erythema and pseudopods) was $\geq 3 \mathrm{~mm}$ larger than that of negative controls. Skin reactivity was considered positive when there was positivity to at least one allergen. In the case of children using antihistamines at the time of the skin test, information was obtained on when the treatment would end and these children were then reevaluated later. In the case of a negative histamine result, information was requested on any recent antihistamine treatment and the child was re-evaluated later in accordance with the half-life of the medication.

Blood samples were collected for measuring allergenspecific IgE for $P$. americana, D. pteronyssinus, B. tropicalis and $B$. germanica using commercial ImmunoCAP kits (Pharmacia Diagnostic, Uppsala, Sweden). Allergenspecific IgE was defined in $\mathrm{kU} / 1$. The lower detection limit was $0.35 \mathrm{kU} / 1$. For the purposes of this analysis, the presence of allergen-specific IgE in each child was defined as (0) non-detectable $(<0 \cdot 35 \mathrm{kU} / \mathrm{l})$ and (1) detectable $(\geq 0.35 \mathrm{kU} / \mathrm{l})$ in concentrations. In addition, concentrations of serum IgE for the detection of allergens ( $\geq 0 \cdot 70 \mathrm{kU} / 1)$ were also tested.

Spirometry was performed in accordance with the recommendations of the American Thoracic Society ${ }^{(26)}$, using a Koko ${ }^{\circledR}$ spirometer (Pulmonary Data Services Instrumentation, Louisville, CO, USA). During the test, the children remained standing with their head in a neutral position. Children who showed evidence of not having performed the examination correctly, such as cases of early cessation, glottic closure or coughing, as well as those who were uncooperative, were excluded from the study. The volumes measured were forced vital capacity (FVC) and forced expiratory volume in $1 \mathrm{~s}$ (FEV1). The bronchodilation test was performed by inhaling salbutamol $200 \mu \mathrm{g}$, with spirometry being performed $15 \mathrm{~min}$ after administration of the bronchodilator. Response to the bronchodilator was considered positive when there was an increase of $\geq 12 \%$ in FEV1 and $\geq 200 \mathrm{ml}$ in its absolute value in relation to the value measured before inhalation of the short-acting $\beta 2$ agonist. The program used by the spirometer permitted predicted percentage values to be automatically calculated for each patient in accordance with the Brazilian standard curve ${ }^{(27)}$. Since few children had results below normal (i.e. $<80 \%$ ) for FEV1:FVC ratio or the Tiffeneau index, the median (98\%) of the percentages obtained when the value found was compared with the predicted value was used for the purpose of analysis in the present study.

\section{Statistical analyses}

The prevalence rates of asthma, atopic sensitivity and wheezing in the past 12 months were calculated as a measure of occurrence and compared between the exposure groups using prevalence ratios (PR) as a measurement of association. Since the study outcome is not a rare event, overestimation of OR may be observed as compared with the PR. Therefore, rather than using logistic regression, multivariate Poisson regression models were defined with robust variance ${ }^{(28,29)}$. Unadjusted associations between dependent variables and other variables were examined using the $\chi^{2}$ test, and the Student's $t$ test was used to examine BMI in $Z$-scores.

Multivariate analyses were performed using Poisson regression models to identify possible confounding factors and effect-modifying covariables. The interaction was interpreted as a change in the magnitude of the effect in the presence of a third variable using the Wald test. The variables were classified as interaction variables' when the $\chi^{2}$ reached a $P$ value $\leq 0 \cdot 10$.

The statistical criteria adopted to recognize confounding factors were based on a variation of at least $10 \%$ in the measurement of the principal association when the crude PR was compared with the adjusted PR. The backward elimination procedure was adopted for this analysis, also taking the epidemiological criteria into consideration $^{(30,31)}$. Missing data in the breast-feeding variable, although consisting of only two cases in this sample, were recovered by imputation, using the median value of the duration of breast-feeding.

As previously described, allergen skin-test reactivity, serum IgE, FEV1:FVC ratio, wheezing in the 12 months before the interview and asthma were considered dependent variables, with BMI as the independent variable. In the statistical analysis, the following were considered as risk categories, according to previous studies, in the adjustment variables: being male; $<6$ years of age; birth weight $<2500$ g; poor maternal educational level; having more than one child under 5 years of age living in the home; $<2$ months of breast-feeding; father or mother having asthma; and infection by Ascaris lumbricoides or Trichuris trichiura. The cut-off age was 6 years because asthma is higher among young children.

The Epi Info statistical software program version $6 \cdot 4$ (Centers for Disease Control and Prevention, Atlanta, GA, USA) was used for data entry and all statistical analyses were performed using STATA statistical software package version 9.0 (StataCorp., College Station, TX, USA).

The protocol of the present study was submitted to the Institutional Review Board of the Institute of Collective Health, Federal University in Bahia, and approved before initiation. Results of the stool tests (both positive and negative) were returned to the children's parents. In the case of positive test results, the children received the appropriate treatment. When necessary, nutritional orientation was provided to the child's parent or guardian. 


\section{Results}

A total of 1445 children aged 4-12 years were selected to constitute the cohort. For the effects of analysis, children were only included if their data for the variables that were analysed in the study were complete. Consequently, children with incomplete data were excluded from the study; however, there were no statistically significant differences between the groups. Therefore, the final sample included in the study consisted of 604 boys and 525 girls, adding up to a total of 1129 children of 4-12 years of age. The anthropometric characteristics of the children are shown in Table 1.

The mean BMI $Z$-score and SD show that children with positive skin reactions and lower FEV1:FVC ratios had significantly higher mean BMI (Table 2). With respect to the events investigated, $29 \cdot 1 \%$ of the children (329 of 1129) had wheezing in the 12 months before the interview, $22 \cdot 8 \%$ (257 of 1129) had symptoms of asthma, $29.9 \%$ (328 of 1098) had a skin reaction to some of the allergens tested and $48 \cdot 6 \%$ (523 of 1075) had a serum IgE level $\geq 0.35 \mathrm{kU} / 1$. Overweight and obesity was identified in $15 \cdot 3 \%$ (173 of 1129) of the children. Positivity for A. lumbricoides infection was found in $16 \cdot 9 \%$ (191 of 1129) and for T. trichiura in $14 \%$ of children (158 of 1129; data not shown).

In the bivariate analysis, statistically significant differences were found between the sexes with respect to sensitivity to allergens and $\operatorname{IgE} \geqslant 0.35 \mathrm{kU} / 1$, with boys being more sensitive than girls. Boys also had lower FEV1:FVC ratios compared with girls. The prevalence of wheezing in the 12 months before the interview and of asthma symptoms was greater in children under 6 years of age and in those infected with $A$. lumbricoides. In the absence of both this parasite and T. trichiura, the prevalence of skin reactivity to allergens was significantly higher. In the children belonging to mothers with better educational levels, the prevalence of positive skin reactivity was also higher (Table 3).

The results of regression models for the estimation of crude and adjusted associations between BMI and allergen skin-test reactivity, serum-specific IgE, FEV1:FVC ratio, wheezing in the past 12 months and asthma symptoms are shown in Table 4. A statistically significant association was found between overweight and skin reactivity; however, this significance was lost following adjustment for confounding factors ( $\mathrm{PR}=1 \cdot 25$, 95\% CI $1 \cdot 00,1 \cdot 56)$. Statistically significant differences were found

Table 1 Anthropometric characteristics of the children according to gender and age

\begin{tabular}{|c|c|c|c|c|c|c|c|c|}
\hline & \multicolumn{4}{|c|}{$<6$ years of age } & \multicolumn{4}{|c|}{$\geq 6$ years of age } \\
\hline & \multicolumn{2}{|c|}{ Male (n 227) } & \multicolumn{2}{|c|}{ Female ( $n$ 195) } & \multicolumn{2}{|c|}{ Male (n 377) } & \multicolumn{2}{|c|}{ Female ( $n$ 330) } \\
\hline & Mean & SD & Mean & SD & Mean & SD & Mean & SD \\
\hline Birth weight (g) & $3248 \cdot 87$ & $491 \cdot 548$ & $3019 \cdot 65$ & $544 \cdot 287$ & $3276 \cdot 55$ & $513 \cdot 504$ & $3248 \cdot 87$ & $491 \cdot 548$ \\
\hline Height $(\mathrm{cm})$ & $111 \cdot 37$ & $6 \cdot 820$ & $109 \cdot 94$ & $5 \cdot 842$ & $128 \cdot 45$ & $8 \cdot 723$ & $111 \cdot 37$ & $6 \cdot 820$ \\
\hline Weight (kg) & $19 \cdot 32$ & $3 \cdot 895$ & $18 \cdot 17$ & $3 \cdot 028$ & $26 \cdot 44$ & $6 \cdot 014$ & $19 \cdot 32$ & $3 \cdot 895$ \\
\hline BMI Z-score & 0.02 & $1 \cdot 278$ & 0.30 & $1 \cdot 051$ & $-0 \cdot 17$ & $1 \cdot 233$ & 0.02 & $1 \cdot 278$ \\
\hline
\end{tabular}

Table 2 Mean BMI Z-scores, according to asthma symptoms, atopy markers and lung function

\begin{tabular}{|c|c|c|c|c|}
\hline \multirow[b]{2}{*}{ Dependent variable } & \multicolumn{4}{|c|}{ BMI Z-score } \\
\hline & $n$ & Mean & SD & $P$ valuet \\
\hline \multicolumn{5}{|l|}{ Skin test } \\
\hline Positive & 328 & -0.024 & $1 \cdot 223$ & \multirow[t]{2}{*}{$0 \cdot 012^{*}$} \\
\hline Negative & 770 & -0.218 & $1 \cdot 141$ & \\
\hline \multicolumn{5}{|l|}{ Specific IgE } \\
\hline Positive & 523 & $-0 \cdot 130$ & $1 \cdot 212$ & \multirow[t]{2}{*}{$0 \cdot 318$} \\
\hline Negative & 552 & $-0 \cdot 201$ & $1 \cdot 118$ & \\
\hline \multicolumn{5}{|c|}{ Wheezing in the past 12 months } \\
\hline Yes & 329 & $-0 \cdot 138$ & $1 \cdot 197$ & \multirow[t]{2}{*}{0.584} \\
\hline No & 800 & $-0 \cdot 180$ & $1 \cdot 160$ & \\
\hline \multicolumn{5}{|l|}{ Asthma symptoms } \\
\hline Yes & 257 & $0 \cdot 110$ & $1 \cdot 247$ & \multirow{2}{*}{$0 \cdot 371$} \\
\hline No & 872 & $-0 \cdot 184$ & $1 \cdot 147$ & \\
\hline \multicolumn{5}{|l|}{ FEV1:FVC ratio (\%) } \\
\hline$\leq 98$ & 394 & -0.052 & $1 \cdot 236$ & \multirow[t]{2}{*}{$0.000^{*}$} \\
\hline$>98$ & 471 & -0.297 & $1 \cdot 101$ & \\
\hline
\end{tabular}

FEV1, forced expiratory volume in $1 \mathrm{~s}$; FVC, forced vital capacity.

Uncontrolled analysis.

${ }^{\star} P<0.05$.

+Student's $t$ test. 
Table 3 The prevalence of study endpoints according to the characteristics of the sample

\begin{tabular}{|c|c|c|c|c|c|c|c|c|c|c|c|c|c|c|c|}
\hline \multirow[b]{2}{*}{ Variable } & \multicolumn{3}{|c|}{$\begin{array}{c}\text { Wheezing in the past } 12 \text { months } \\
\qquad(n 1129) \\
\text { Yes }(n \text { 329) }\end{array}$} & \multicolumn{3}{|c|}{$\begin{array}{l}\text { Asthma symptoms } \\
(n 1129) \\
\text { Yes }(n 257)\end{array}$} & \multicolumn{3}{|c|}{$\begin{array}{c}\text { Skin reactivity } \\
(n 1098) \\
\text { Positivity }(n 328)\end{array}$} & \multicolumn{3}{|c|}{$\begin{array}{c}\mathrm{IgE} \geq 0.35 \mathrm{kU} / \mathrm{l} \\
(n 1075) \\
\text { Positivity }(n 523)\end{array}$} & \multicolumn{3}{|c|}{$\begin{array}{l}\text { FEV1:FVC ratio } \\
(n 865) \\
\leq 98 \%(n 394)\end{array}$} \\
\hline & $n$ & $\%+$ & $P$ value $\ddagger$ & $n$ & $\%+$ & $P$ value $\neq$ & $n$ & $\%+$ & $P$ value $\ddagger$ & $n$ & $\%+$ & $P$ value $\ddagger$ & $n$ & $\%+$ & $P$ value \\
\hline \multicolumn{16}{|l|}{ Gender } \\
\hline Male & 171 & $28 \cdot 3$ & 0.511 & 142 & $23 \cdot 5$ & 0.521 & 194 & $32 \cdot 9$ & $0 \cdot 017^{*}$ & 314 & $54 \cdot 6$ & $0.000^{*}$ & 238 & $39 \cdot 4$ & $0 \cdot 000^{*}$ \\
\hline Female & 158 & $30 \cdot 1$ & & 115 & $21 \cdot 9$ & & 134 & $26 \cdot 3$ & & 209 & $41 \cdot 8$ & & 156 & $25 \cdot 8$ & \\
\hline \multicolumn{16}{|l|}{ Age (years) } \\
\hline$\geq 6$ & 155 & $21 \cdot 9$ & $0.000^{*}$ & 121 & $17 \cdot 1$ & $0.000^{*}$ & 211 & $30 \cdot 7$ & $0 \cdot 431$ & 337 & $49 \cdot 7$ & $0 \cdot 366$ & 255 & $23 \cdot 0$ & 0.687 \\
\hline$<6$ & 174 & $41 \cdot 2$ & & 136 & $32 \cdot 2$ & & 117 & $28 \cdot 5$ & & 186 & $46 \cdot 9$ & & 139 & $42 \cdot 2$ & \\
\hline \multicolumn{16}{|l|}{ Birth weight $(\mathrm{g})$} \\
\hline $\begin{array}{l}<2500 \\
\geq 2500\end{array}$ & $\begin{array}{r}34 \\
295\end{array}$ & $\begin{array}{l}33 \cdot 0 \\
28 \cdot 8\end{array}$ & 0.365 & $\begin{array}{r}30 \\
227\end{array}$ & $\begin{array}{l}29 \cdot 1 \\
22 \cdot 1\end{array}$ & $0 \cdot 106$ & $\begin{array}{r}24 \\
304\end{array}$ & $\begin{array}{l}24 \cdot 2 \\
30 \cdot 4\end{array}$ & $0 \cdot 199$ & $\begin{array}{r}41 \\
482\end{array}$ & $\begin{array}{l}42 \cdot 7 \\
49 \cdot 2\end{array}$ & $0 \cdot 222$ & $\begin{array}{r}32 \\
362\end{array}$ & $\begin{array}{l}40 \cdot 0 \\
46 \cdot 1\end{array}$ & $0 \cdot 295$ \\
\hline \multicolumn{16}{|l|}{ Breast-feeding (months) } \\
\hline$<2$ & 222 & $29 \cdot 9$ & 0.449 & 174 & $23 \cdot 4$ & 0.466 & 211 & $29 \cdot 1$ & 0.438 & 347 & $48 \cdot 9$ & $0 \cdot 790$ & 267 & $46 \cdot 4$ & 0.502 \\
\hline$\geq 2$ & 107 & $27 \cdot 7$ & & 83 & $21 \cdot 5$ & & 117 & $31 \cdot 4$ & & 176 & $48 \cdot 1$ & & 127 & $43 \cdot 9$ & \\
\hline \multicolumn{16}{|l|}{$\begin{array}{l}\text { Number of children }<5 \text { years } \\
\text { of age in the household }\end{array}$} \\
\hline$\leq 1$ & 194 & $28 \cdot 1$ & 0.322 & 155 & $22 \cdot 4$ & $0 \cdot 738$ & 220 & $32 \cdot 8$ & $0.008^{*}$ & 311 & $47 \cdot 6$ & $0 \cdot 403$ & 243 & $46 \cdot 5$ & 0.505 \\
\hline$>1$ & 135 & $30 \cdot 8$ & & 102 & $23 \cdot 3$ & & 108 & $25 \cdot 3$ & & 212 & $50 \cdot 2$ & & 151 & $44 \cdot 2$ & \\
\hline \multicolumn{16}{|l|}{ Mother's schooling } \\
\hline University/high school & 71 & $29 \cdot 6$ & $0 \cdot 911$ & 51 & $21 \cdot 3$ & 0.520 & 93 & $40 \cdot 3$ & $0 \cdot 000^{*}$ & 118 & $52 \cdot 0$ & $0 \cdot 160$ & 82 & $46 \cdot 9$ & 0.630 \\
\hline Did not finish high school & 176 & $28 \cdot 6$ & & 137 & $22 \cdot 3$ & & 155 & $25 \cdot 7$ & & 269 & $46 \cdot 0$ & & 209 & $44 \cdot 1$ & \\
\hline Illiterate & 82 & $29 \cdot 9$ & & 69 & $25 \cdot 2$ & & 80 & $30 \cdot 2$ & & 136 & $51 \cdot 7$ & & 103 & $47 \cdot 7$ & \\
\hline \multicolumn{16}{|l|}{ Ascaris lumbricoides infection } \\
\hline Yes & 70 & $36 \cdot 6$ & $0 \cdot 012^{*}$ & 55 & $28 \cdot 8$ & $0 \cdot 029^{*}$ & 43 & $22 \cdot 9$ & $0 \cdot 021^{*}$ & 90 & $48 \cdot 4$ & 0.937 & 73 & $50 \cdot 3$ & $0 \cdot 204$ \\
\hline No & 259 & $27 \cdot 6$ & & 202 & $21 \cdot 5$ & & 285 & $31 \cdot 3$ & & 433 & $48 \cdot 7$ & & 321 & $44 \cdot 6$ & \\
\hline \multicolumn{16}{|l|}{ Trichuris trichiura infection } \\
\hline Yes & 50 & $31 \cdot 6$ & $0 \cdot 455$ & 39 & $24 \cdot 7$ & 0.535 & 33 & $21 \cdot 2$ & $0 \cdot 010$ & 73 & $46 \cdot 8$ & 0.616 & 60 & $49 \cdot 6$ & 0.336 \\
\hline No & 279 & $28 \cdot 7$ & & 218 & $22 \cdot 5$ & & 295 & $31 \cdot 3$ & & 450 & $49 \cdot 0$ & & 334 & $44 \cdot 9$ & \\
\hline
\end{tabular}

${ }^{*} P<0.05$.

+ Prevalence.
$\ddagger \chi^{2}$ test. 
Table 4 Prevalence rates and PR of the study endpoints according to BMI

\begin{tabular}{|c|c|c|c|c|c|c|}
\hline & $n$ & $\%$ & $\mathrm{PR} \dagger$ & $95 \% \mathrm{Cl}$ & PR $\ddagger$ & $95 \% \mathrm{Cl}$ \\
\hline \multicolumn{7}{|l|}{ Skin reactivity } \\
\hline Normal weight/deficit & 261 & $28 \cdot 1$ & 1 & - & 1 & - \\
\hline Overweight/obesity & 67 & $39 \cdot 9$ & $1 \cdot 42^{*}$ & $1 \cdot 15,1 \cdot 73$ & $1 \cdot 25$ & $1 \cdot 00,1.56$ \\
\hline \multicolumn{7}{|l|}{ Specific IgE } \\
\hline Normal weight/deficit & 435 & $47 \cdot 6$ & 1 & - & 1 & - \\
\hline Overweight/obesity & 88 & $54 \cdot 7$ & $1 \cdot 15$ & $0.99,1.34$ & $1 \cdot 10$ & $0 \cdot 95,1 \cdot 3 c$ \\
\hline \multicolumn{7}{|c|}{ Wheezing in the past 12 months } \\
\hline Normal weight/deficit & 278 & $29 \cdot 1$ & 1 & - & 1 & - \\
\hline Overweight/obesity & 51 & $29 \cdot 5$ & $1 \cdot 01$ & $0 \cdot 78,1 \cdot 31$ & $1 \cdot 14$ & $0.91,1 \cdot 41$ \\
\hline \multicolumn{7}{|l|}{ Asthma symptoms } \\
\hline Normal weight/deficit & 212 & $22 \cdot 2$ & 1 & - & 1 & - \\
\hline Overweight/obesity & 45 & $26 \cdot 0$ & $1 \cdot 17$ & $0.89,1.54$ & $1 \cdot 34^{*}$ & $1.07,1.67$ \\
\hline \multicolumn{7}{|l|}{ FEV1:FVC ratio } \\
\hline Normal weight/deficit & 315 & $43 \cdot 1$ & 1 & - & 1 & - \\
\hline Overweight/obesity & 79 & $59 \cdot 0$ & $1 \cdot 37^{\star}$ & $1 \cdot 14,1 \cdot 64$ & $1 \cdot 35^{\star}$ & $1 \cdot 11,1 \cdot 61$ \\
\hline
\end{tabular}

$\mathrm{PR}$, prevalence ratio; overweight/obesity, BMI Z-score $\geq+1$; FEV1, forced expiratory volume in $1 \mathrm{~s}$; FVC, forced vital capacity.

${ }^{*} \mathrm{PR}$ and $95 \% \mathrm{Cl}$ significant $(P<0.05)$.

tCrude PR.

¥PR adjusted for gender, age, birth weight, parental history of asthma, breast-feeding, number of children under 5 years of age in the household, mother's educational level, infection by Ascaris lumbricoides, infection by Trichuris trichiura.

Table 5 Prevalence rates and PR of skin test reactivity, asthma symptoms and wheezing in the 12 months preceding the interview in overweight children according to the duration of breast-feeding

\begin{tabular}{|c|c|c|c|c|c|c|}
\hline & $n$ & $\%$ & $\mathrm{PR}+$ & $95 \% \mathrm{Cl}$ & PR $\ddagger$ & $95 \% \mathrm{Cl}$ \\
\hline \multicolumn{7}{|c|}{ Skin reactivity } \\
\hline \multicolumn{7}{|c|}{ Breast-feeding (months) } \\
\hline$<2$ & 211 & $29 \cdot 1$ & $1 \cdot 50^{*}$ & $1 \cdot 15,1.96$ & $1 \cdot 28^{*}$ & $1 \cdot 01,1 \cdot 70$ \\
\hline$\geq 2$ & 117 & $31 \cdot 4$ & $1 \cdot 27$ & $0.92,1.75$ & $0 \cdot 76$ & $0.41,1 \cdot 40$ \\
\hline \multicolumn{7}{|c|}{ Asthma symptoms } \\
\hline \multicolumn{7}{|c|}{ Breast-feeding (months) } \\
\hline$<2$ & 174 & $23 \cdot 4$ & $1 \cdot 40$ & $1.01,1.93$ & $1 \cdot 53^{*}$ & $1 \cdot 11,2 \cdot 09$ \\
\hline$\geq 2$ & 83 & $21 \cdot 5$ & 0.72 & $0.89,1.32$ & $0 \cdot 81$ & $0.44,1.49$ \\
\hline
\end{tabular}

$\mathrm{PR}$, prevalence ratio; $n$, total number of cases in each category of breast-feeding.

${ }^{*} \mathrm{PR}$ and $95 \% \mathrm{Cl}$ significant $(P<0.05)$

tCrude PR.

‡PR adjusted for gender, age, birth weight, parental history of asthma, breast-feeding, number of children under 5 years of age in the household, mother's educational level, infection by Ascaris lumbricoides, infection by Trichuris trichiura.

between overweight and asthma symptoms and between overweight and FEV1:FVC ratio, even after adjustment. Compared with the group of normal and underweight children, the prevalence of asthma symptoms and lower FEV1:FVC ratios were $>34 \%$ and $35 \%$, respectively, in the group of overweight children (Table 4). Serum IgE levels $\geq 0 \cdot 70 \mathrm{kU} / 1$ for the detection of allergens were also tested in the multivariate analysis (data not shown) and no statistically significant differences were found in the results obtained at levels $\geq 0.35 \mathrm{kU} / 1$.

The duration of breast-feeding was confirmed as an effect modifier of the associations between overweight and skin reactivity and between overweight and asthma symptoms, indicating that the analyses should be stratified in accordance with this variable (Table 5). In the children who had been breast-fed for $<2$ months, skin-test positivity was more common when the child was overweight compared with normal or underweight children ( $\mathrm{PR}=1 \cdot 28,95 \%$ CI 1.01, 1.70) even after adjustment for confounding factors. Likewise, a $53 \%$ higher prevalence of asthma symptoms was found in overweight children who had been breast-fed for $<2$ months compared with normal or underweight children (PR $=1 \cdot 53$; $95 \%$ CI $1 \cdot 11$, 2.09; Table 5).

\section{Discussion}

In the present study population, the prevalence rates of wheezing in the past 12 months and of asthma, defined according to reported symptoms, were high (>20\%), which was consistent with findings from other studies, placing Brazil among the countries with the highest prevalence rates of this disease in children ${ }^{(32)}$. On the other hand, the prevalence of overweight and obesity (15.3\%) in the study population is similar to that found in the literature for children of the same age group in Salvador $(15 \cdot 8 \%)^{(33)}$ and lower than that found by Suñé et $a l^{(34)}$ in the south of Brazil $(24 \cdot 8 \%)$, although it should be emphasized that comparison with previous studies is 
difficult because of the diversity of criteria used for the definition of nutritional status since no standard or reference was agreed upon internationally ${ }^{(35)}$. Different estimates of nutritional status may also be found when factors such as age, gender and also the time at which the study was conducted are taken into consideration, especially in Brazil where rapid nutritional transition has been observed over the past 10 years ${ }^{(36)}$.

Our results corroborate similar findings in different contexts and with different methodologies that have reported the existence of a positive association between the occurrence of overweight and asthma symptoms in children. In the present study, overweight children had $34 \%$ more asthma, even after adjusting for potential confounders. Several studies conducted worldwide in children or adults have indicated the existence of a statistically significant association between obesity and asthma $^{(3,7,13)}$, with few publications suggesting the reverse and these consisting predominantly of casecontrol studies with limited sample sizes ${ }^{(37)}$. In a study conducted on 14908 English and Scottish children of 4-11 years of age, who participated in the National Study of Health and Growth, the risk of asthma was found to be $28 \%$ higher in obese children compared with those of normal weight ${ }^{(38)}$. Obesity was also associated with wheezing, a precursor of diagnosis of asthma, in the 12 months preceding the interview in children under 5 years of age living in fourteen townships in Bahia and São Paulo. The authors found a $2.57 \%$ higher risk of the occurrence of wheezing in obese children ${ }^{(40)}$.

Another important finding in the present study was the interrelationship between overweight, breast-feeding and asthma. A shorter duration of breast-feeding combined with overweight was significantly associated with asthma and positive allergen skin-test reactivity. Overweight children who were breast-fed for $<2$ months had $32 \%$ more skin reactivity and $54 \%$ more asthma. This finding is in agreement with the results published by Oddy et al. ${ }^{(41)}$, who investigated a cohort of Australian-born children of up to 6 years of age. In that study, a shorter duration of breast-feeding increased the likelihood of the child developing asthma, atopy or overweight in the future, the latter being a risk factor for asthma. In another study conducted by the same investigator, each additional month of breast-feeding contributed towards a reduction in the risk of developing overweight ${ }^{(42)}$. It is suggested that a common pathway between asthma and obesity and the short duration of breast-feeding may be a common influence on overweight and asthma ${ }^{(37)}$. Children who were breast-fed for a short time early in life could have low levels of circulating leptin, which is a hormone present in breast milk and inversely associated with weight gain in infancy, and the risk of overweight and asthma could be higher in later life ${ }^{(37)}$. Unfortunately, in this population, leptin was unavailable. We would suggest that future studies should be carried out in which leptin and adiponectin levels are taken into consideration in order to acquire further information on their role in the occurrence of asthma and atopy in these children.

Moreover, asthma causes airway inflammation, and the proinflammatory state of obesity as a consequence of the endocrine activity of adipose tissue is known to be associated with wheezing and asthma ${ }^{(3,42)}$. The macrophages present in adipose tissue, particularly those found in central or visceral obesity, are a source of inflammatory mediators such as inflammatory adipokines, leptin and ghrelin, and of inflammatory markers such as IL-6, IL-18, $\mathrm{TNF}-\alpha$ and C-reactive protein. Insulin resistance is also associated with the occurrence of asthma symptoms and obesity and asthma may be related to the same inflammatory trajectory ${ }^{(11,12)}$.

In the present study, overweight children also have less respiratory capacity, as reflected in lower FEV1:FVC ratios. This association was robust and persisted even after inclusion of potential confounding factors into the model. Pulmonary function has been consistently shown in the literature to be impaired in the presence of obesity $^{(3,42)}$. Pulmonary volume is inversely proportional to the degree of adiposity, the reasons for the reduction being associated with mechanical effects. Obesity is known to be a restrictive process that promotes alterations in pulmonary volume and in total lung capacity, with a reduction in expiratory reserve volume and functional residual capacity. Flow volume is low in the respiration of obese individuals and airway smooth muscle becomes shortened, also leading to constriction and rigidity of the airways, which in turn contribute towards lower airway surface tension, resulting in an unfavourable cycle that is detrimental to lung function. Obesity does not directly cause airway obstruction, but may lead to airway hyper-responsiveness, one of the clinical characteristics of asthma through the mechanisms described previously ${ }^{(3,42)}$.

Allergen skin test also showed that, when the individual was not infected by $A$. lumbricoides or T. trichiura, the prevalence of allergen skin-test positivity was significantly higher. Geohelminths infections are known to be negatively associated with atopy. Mechanisms that have been proposed include the induction of regulatory $\mathrm{T}$ cells, which are able to suppress allergic effector responses at distal sites, and generation of an immunosuppressive environment in the host organism ${ }^{(44)}$.

The present study took advantage of being part of a large prospective cohort study that collected data in early childhood on variables that could interfere with the associations studied. Nevertheless, the results are subject to the inherent limitations of a study design. The first limitation, typical of any observational study, is the impossibility of controlling all the possible confounders; thus it becomes impossible to rule out residual confounding related to the principal association. Moreover, since it is a cross-sectional study in which overweight and 
asthma were measured simultaneously, the researchers' possibilities for inferring causal relationships based on the observed associations should be weighed with caution.

There is a consensus that a longer duration of breastfeeding protects infants against asthma and allergies as well as from other diseases ${ }^{(45)}$, although previous studies showed that breast-feeding and the duration of breastfeeding do not seem to have a significant impact on the rates of asthma in late childhood ${ }^{(46)}$. Other studies have shown that the protective effect of breast-feeding appears to be greater in children with a family history of atopy, particularly in those who live in less-developed countries $^{(47)}$. This fact may have led to controversies in the findings of studies in which the objective was to evaluate the association between breast-feeding, asthma and other allergic diseases ${ }^{(47)}$. Another explanation for these findings lies in the hygiene hypothesis. The protection against infections conferred by breast-feeding may induce the immune system to a Th2 profile, thus increasing the risk of atopy ${ }^{(47)}$.

Nutritional factors have received more attention in recent years as a possible way of preventing and treating chronic diseases. Particularly in the case of asthma and atopy, diseases with few possibilities for prevention, the promotion of breast-feeding, a healthy diet and maintenance of adequate weight have come to represent a real possibility in the prevention and control of these conditions and in maintaining patients' quality of life. Particularly in childhood, the possibility of prevention is even greater. On the other hand, both asthma and obesity constitute significant public health issues that cause an impact on hospitalization rates and mortality, a fact that heightens interest in studies and interventions aimed at reducing the occurrence of these two problems in the population. Understanding the mechanisms involved in the association between obesity and asthma, in addition to providing further data on how they are associated, may contribute towards the development of new therapeutic strategies. Efforts to promote breast-feeding and reduce childhood obesity may lead to a reduction in the occurrence of asthma and atopy.

\section{Acknowledgements}

The present study was funded by The Wellcome Trust, UK, HCPC Latin America Excellence Centre Programme, Ref. 072405/Z/03/Z. The previous studies conducted with the same cohort were supported by the Programa de Núcleo de Excelência (PRONEX-CNPq/MCT, Brazil), Contract no. 66.1086/1998-4, and by The Bahia State Government Department of Urban Development, Brazil. S.d.M.S. was supported by the Foundation for the Support of Research in the State of Bahia (FAPESB), Brazil (1941/ 2006). The authors have no conflict of interest to declare. S.M.A.M. was responsible for writing this manuscript;
M.L.B., L.C.R. and A.A.C. obtained the funding and coordinated the study; M.S.P. and M.L.B. designed the methodology for data collection; M.S.P. coordinated and S.M.A.M. participated in collecting the anthropometric data; S.d.M.S. supervised and participated in collecting the spirometry test data; N.M.A.-N. supervised the parasitological analysis of faeces samples and the detection of IgE antibodies; S.R.J., S.M.A.M. and S.R.D.M.S. conducted the statistical analyses; A.M.O.A., S.M.A.M. and S.D.I. contributed by critically reviewing the manuscript. All the authors contributed to reviewing the manuscript and are in agreement with respect to its submission. The authors thank the children and parents who participated in the present study.

\section{References}

1. World Health Organization (2000) Obesity: Preventing and Managing the Global Epidemic. WHO Technical Report Series no. 894. Geneva: WHO.

2. Masoli M, Fabian D, Holt S et al. (2004) The global burden of asthma: executive summary of the GINA Dissemination Committee report. Allergy 59, 469-478.

3. Beuther DA (2009) Obesity and asthma. Clin Chest Med 30, 479-488.

4. Litonjua AA \& Gold DR (2008) Asthma and obesity: common early-life influences in the inception of disease. J Allergy Clin Immunol 121, 1075-1084.

5. Monteiro CA, Conde WL \& Popkin BM (2004) The burden of disease from undernutrition and overnutrition in countries undergoing rapid nutrition transition: a view from Brazil. Am J Public Health 94, 433-434.

6. Solé D, Wandalsen GF, Camelo-Nunes IC et al. (2006) Prevalence of symptoms of asthma, rhinitis, and atopic eczema among Brazilian children and adolescents identified by the International Study of Asthma and Allergies in Childhood (ISAAC) Phase 3. J Pediatr 82, 341-346.

7. Chinn S \& Rona RJ (2001) Can the increase in body mass index explain the rising trend in asthma in children? Thorax 56, 845-850.

8. Flaherman V \& Rutherford GW (2006) A meta-analysis of the effect of high weight on asthma. Arch Dis Child $\mathbf{9 1}$, 334-339.

9. Plumb J, Brawer R \& Brisbon N (2007) The interplay of obesity and asthma. Curr Allergy Asthma Rep 7, 385-389.

10. Kronander UN, Falkenberg M \& Zetterstrom O (2004) Prevalence and incidence of asthma related to waist circumference and BMI in a Swedish community sample. Respir Med 98, 1108-1116.

11. Al-Shawwa BA, Al-Huniti NH, DeMattia L et al. (2007) Asthma and insulin resistance in morbidly obese children and adolescents. J Asthma 44, 469-473.

12. Bidad K, Anari S, Aghamohammadi A et al. (2007) Prevalence of asthma related to BMI in adolescents in Tehran, Iran, 2004-2005. Eur J Pediatr 166, 453-454.

13. Jartti T, Saarikoski L, Jartti L et al. (2009) Obesity, adipokines and asthma. Allergy 64, 770-777.

14. Al-Shawwa B, Al-Huniti N, Titus G et al. (2006) Hypercholesterolemia is a potential risk factor for asthma. J Asthma 43, 231-233.

15. Matricardi PM, Grüber C, Wahn U et al. (2007) The asthma-obesity link in childhood: open questions, complex evidence, a few answers only. Clin Exp Allergy 37, 476-484. 
16. Teixeira MG, Barreto ML, Costa MC et al. (2002) Sentinel areas: a monitoring strategy in public health. Cad Saude Publica 18, 1189-1195.

17. Barreto ML, Strina A, Prado M et al. (1997) Saneamento básico e saúde: fundamentos científicos para avaliação do impacto epidemiólogico do programa de saneamento ambiental da Bahia de Todos os Santos (Bahia Azul). In Saneamento e Saúde nos Países em Desenvolvimento, pp. 7-35 [L Heller, LR Moraes, TC Monteiro et al., editors]. Rio de Janeiro: CC\&P Editores.

18. Barreto ML, Cunha SS, Alcântara-Neves N et al. (2006) Risk factors and immunological pathways for asthma and other allergic disease in children: background and methodology of a longitudinal study in a large urban center in Northeastern Brazil (Salvador-SCAALA study). BMC Pulm Med 6, 15.

19. Rodrigues LC, Newcombe PJ, Cunha SS et al. (2008) SCAALA (Social Change Asthma and Allergy in Latin America). Early infection with Trichuris trichiuria and allergen skin test reactivity in later childhood. Clin Exp Alergy 38, 1769-1777.

20. Organización Mundial de la Salud (1995) El Estado Físico: Uso e Interpretación de la Antropometría. Série de Informes Técnicos 854. Ginebra: Organización Mundial de la Salud.

21. Kuczmarski RJ, Ogden CL, Grummer-Strawn LM et al. (2000) CDC Growth Charts: United States. Advance Data from Vital and Health Statistics no. 314. Hyattsville, MD: National Center for Health Statistics; available at http// www.cdc.gov/growthcharts

22. WHO Multicentre Growth Reference Study Group (2006) WHO Child Growth Standards based on length/height, weight and age. Acta Paediatr 450, 76-85.

23. de Onis M, Onyango A, Borghi E et al. (2007) Development of a WHO growth reference for school-aged children and adolescents. Bull World Health Organ 85, 661-668.

24. Neva FA \& Brown HW (1994) Basic Clinical Parasitology, 6th ed. Norwalk, CT: Appleton \& Lange.

25. Katz N, Chaves A \& Pellegrino J (1972) A simple device for quantitative determination of Schistosoma mansoni eggs in faeces examined by the thick-smear technique. Rev Inst Med Trop São Paulo 14, 394-400.

26. Miller MR, Hankinson J, Brusasco V et al. (2005) Standardisation of spirometry. Eur Respir J 26, 319-338.

27. Pereira CAC (2002) Espirometria. Consenso Brasileiro de Avaliação da Função Pulmonar. J Pneumol 28, Suppl. 3, S1-S8.

28. Barros AJD \& Hirakata VN (2003) Alternatives for logistic regression in cross-sectional studies: an empirical comparison of models that directly estimate the prevalence ratio. BMC Med Res Methodol 3, 1-13.

29. Zou G (2004) A modified Poisson regression approach to prospective studies with binary data. Am J Epidemiol 159, 702-706.

30. Kleinbaum D, Kupper L \& Morgenstern H (1982) Epidemiologic Research. Belmont, CA: Lifetime Learning Publications.
31. Rothman KJ \& Greenland S (1998) Modern Epidemiology. Philadelphia, PA: Lippincott-Raven Publications.

32. Asher MI, Montefort S, Björkstén B et al. (2006) Worldwide time trends in the prevalence of symptoms of asthma, allergic rhinoconjunctivitis, and eczema in childhood: ISAAC Phases One and Three repeat multicountry crosssectional surveys. Lancet 368, 733-743.

33. Leão LSCS, Araújo LMB, Moraes LTLP et al. (2003) Prevalência de obesidade em escolares de Salvador, Bahia. Arq Bras Endocrinol Metab 47, 151-157.

34. Suñé FR, Dias-da-Costa JS, Olinto MTA et al. (2007) Prevalência e fatores associados para sobrepeso e obesidade em escolares de uma cidade no Sul do Brasil. Cad Saúde Pública 23, 1361-1371.

35. Wang Y \& Wang JQ (2002) A comparison of international references for the assessment of child and adolescent overweight and obesity in different populations. Eur J Clin Nutr 56, 973-982.

36. Wang Y, Monteiro C \& Popkin BM (2002) Trends of obesity and underweight in older children and adolescents in the United States, Brazil, China, and Russia. Am J Clin Nutr $\mathbf{7 5}$, 971-977.

37. Mai X-M, Becker AB, Sellers EAC et al. (2007) The relationship of breast-feeding, overweight, and asthma in preadolescents. J Allergy Clin Immunol 120, 551-556.

38. Figueroa-Munoz JI, Chinn S \& Rona RJ (2001) Association between obesity and asthma in 4-11 year old children in the UK. Thorax 56, 133-137.

39. Saldiva SRDM, Escuder MM, Venâncio SI et al. (2008) Is overweight a risk factor for wheezing in pre-school children? A study in 14 Brazilian communities. Public Health Nutr 10, 878-882.

40. Oddy WH, Sherriff JL, Klerk NH et al. (2004) The relation of breastfeeding and body mass index to asthma and atopy in children: a prospective cohort study to age 6 years. Am J Public Health 94, 1531-1537.

41. Oddy WH \& Sherriff JL (2003) Breastfeeding, body mass index, asthma and atopy in children. Asia Pac J Public Health 15, Suppl. 1, S15-S17.

42. Shore SA (2008) Obesity and asthma: possible mechanisms. J Allergy Clin Immunol 121, 1087-1093.

43. Moncayo AL \& Cooper PJ (2006) Geohelminth infections: impact on allergic diseases. Int J Biochem Cell Biol 38, 1031-1035.

44. Oddy WH (2009) The long-term effects of breastfeeding on asthma and atopic disease. Adv Exp Med Biol 639, 237-251.

45. Burgess SW, Dakin JC \& O'Callaghan MJ (2006) Breastfeeding does not increase the risk of asthma at 14 years. Pediatrics 117, e787-e792.

46. Nagel G, Büchele G, Weinmayr G et al. (2009) ISAAC Phase II Study Group. Effect of breastfeeding on asthma, lung function and bronchial hyperreactivity in ISAAC Phase II. Eur Respir J 33, 993-1002.

47. Ducan JM \& Sears MR (2008) Breastfeeding and allergies: time for a change in paradigm? Curr Opin Allergy Clin Immunol 8, 398-405. 